\title{
ENTRE PALAVRAS E VIDA: UMA LEITURA SOBRE DOCUMENTAÇÃO PEDAGÓGICA E NARRATIVA NO CONTEXTO DA EDUCAÇÃO INFANTIL INCLUSIVA
}

Luciane Pandini Simiano ${ }^{1}$

Carla Karnoppi Vasques ${ }^{2}$

\section{Resumo}

O presente texto discute a documentação pedagógica como um percurso narrativo, uma peculiar forma de ler o cotidiano, sustentar o encontro, estar em relação. A partir de uma experiência na educação infantil, o material empírico analisa parte de uma documentação, construída em conjunto com uma criança incluída, seus colegas e familiares. Tal estudo efetivou-se a partir do diálogo entre a filosofia de Walter Benjamin, a psicanálise, o direito à educação e a pedagogia italiana. A escrita de um diário inscreveu a história escolar de Marcello como possibilidade e não como determinação; constituiu o professor como um narrador, atento aos detalhes, aos restos e aos silêncios. Pensar a documentação como narrativa nos lança em uma zona estranha, incerta e fascinante. Um convite a inverter o olhar e pensar uma lógica que vê e narra a pequena criança e sua deficiência não como faltosa ou inábil, mas como força, potência e possibilidade.

\footnotetext{
${ }^{1}$ Pedagoga, especialista em educação infantil. Doutora em Educação pela UFRGS. Atualmente é professora do Programa de Pós-Graduação em Educação da Universidade do Sul de Santa Catarina- UNISUL. Endereço: Avenida Jose Acácio Moreira, 787 Bairro Dehon - Caixa Postal 370 - CEP 88704-900 - Tubarão SC, Brasil Endereço eletrônico: lucianepandini@gmail.com.

${ }^{2}$ Psicóloga, formação em psicanálise. Doutora em Educação pela UFRGS. Atualmente é professora do Programa de Pós-Graduação em Educação da Universidade Federal do Rio Grande do Sul- UFRGS. Endereço: Av. Paulo Gama, $\mathrm{s} / \mathrm{n}^{\circ}$, prédio 12.201, $7^{\circ}$ andar 90046-900 - Porto Alegre/RS, Brasil. Endereço eletrônico: k.recuero@gmail.com
} 
Palavras-chaves: Educação infantil; Inclusão escolar; Documentação Pedagógica; Narrativa

\section{INTRODUÇÃO}

$\mathrm{O}$ atendimento em creche e pré-escola, historicamente, é marcado por ações de guarda e abrigo a crianças pequenas enquanto suas mães trabalhavam. Nas últimas décadas, como fruto de uma longa trajetória de estudos teóricos e militância política, o papel dessas instituições vem sendo questionado, à medida em que a educação passa a ser direito de todos.

Nesse âmbito, as práticas educativas ganham destaque e tornam-se alvo permanente de reflexões. Qual o significado e a função da educação infantil? Quais as melhores metodologias? Como respeitar a diversidade de ritmos e as diferenças entre os sujeitos? Tais perguntas são ainda mais prementes quando falamos de sujeitos com deficiência, cuja presença interroga, causa desconforto e estranhamento. É consensual, entre teóricos e pesquisadores de diferentes campos, a importância do diálogo entre educação infantil e educação especial para o desenvolvimento e constituição subjetiva. Contudo, estudos recentes demonstram a redução nas matrículas, o descompasso entre as políticas de saúde e educação, bem como as dificuldades para sustentar o acesso e a permanência em função de práticas pedagógicas frágeis e incapazes de perceber e valorar as diferentes formas de ser e estar na creche (VICTOR, 2010; BUENO E MELETTI, 2011; BENINCASA, 2011).

Esse texto discute algumas destas questões a partir da experiência de um grupo de quinze crianças, com idade entre três e quatro anos, em uma instituição de educação infantil, localizada em um município da região sul de Santa Catarina, entre os anos de 2009 e 2010. O material empírico apresenta e analisa parte de uma documentação pedagógica, um diário, construído em conjunto com uma criança em situação de inclusão escolar, seus colegas e familiares. Diante das perdas decorrentes do quadro degenerativo grave, era necessário que escola e família oferecessem palavras, imagens, gestos, visibilidades e sentidos atentos a vida pulsante no menino.

Tal proposição efetivou-se a partir do diálogo entre a filosofia de Walter Benjamin, a psicanálise, o direito à educação e a pedagogia italiana. O diário inscreve a história de Marcello na creche como possibilidade e não como determinação, ao criar (in)visibilidades e possibilidades de pertença. Tal argumento é construído tendo o ensaio como método. Para 
Adorno (2003), a escrita ensaística possibilita uma língua diferente para falar de educação. Língua que se abre para sentidos, interpretações, conhecimentos e reconhece a experiência, o movimento da vida. Um tipo de escritura que traz à tona as marcas de subjetividades. Nas palavras de Adorno o ensaio emerge:

(...) da disponibilidade de quem como uma criança, não tem vergonha de se entusiasmar com o que os outros já fizeram. O ensaio reflete o que é amado e odiado, em vez de conceber o espírito a partir do nada. Felicidade e jogo lhe são essenciais". (ADORNO, 2003, p.22).

Ao romper com a escritura de um texto objetivo e linear o ensaio acolhe a interpretação do sujeito, pois refere-se a um saber que nos constitui. O fragmento é sua matéria, "uma citação, um acontecimento, uma paisagem, uma sensação, uma experiência, algo que lhe parece expressivo e isso dá ao ensaio uma grande expressividade" (LARROSA 2003, p. 111). Trata-se então, de uma escritura ínfima, urdida entre palavra e vida, pensamento e experiência. A aposta que fazemos é no ensaio como forma de pensar e dizer a educação. Que histórias estão sendo contadas na/da escola? "Quem ainda encontra pessoas que saibam contar histórias como elas devem ser contadas?” (BENJAMIN, 1986, p. 114)

Com fios da teoria, das normativas legais que fazem margem à experiência vivida, sustenta-se a documentação pedagógica como possibilidade de fazer frente a práticas objetivadoras, normalizadoras, sobretudo, institui-la como um percurso narrativo, uma forma singular de ler o cotidiano, de sustentar o encontro e os processos inclusivos.

\section{TEMPOS DE ENCONTROS...}

2009. Início de ano. Um dia de sol radiante de verão aquece a chegada na creche. Os pequenos com o coração batendo acelerado adentram a sala. Múltiplas sensações. Variados encontros. Olhares desconfiados, sorrisos abertos, gestos tímidos e abraços apertados. Significações singulares. No ar, um cheiro de novidade. Entre adultos e crianças, inúmeras expectativas, vivências, (des)encontros e apostas passam a constituir a vida em um contexto coletivo de educação. Nesse processo, o desafio de construir um encontro, permitindo-se tocar e ser tocado por semelhanças e diferenças...

À margem da agenda política do Estado, a educação especial tradicionalmente se organizou como atendimento educacional especializado substitutivo ao ensino comum, em classes e escolas especiais. Espaços e propostas diferenciados para aqueles que por suas 
qualidades sociais, culturais, genéticas e comportamentais diferiam da normalidade. Para as lentes do Estado, dos professores e dos especialistas, ser diferente era ser desigual, justificando a desigualdade a educação, de acesso e permanência na em instituições educativas.

A persistência, o crescimento e aprofundamento deste quadro, em conjunto com a universalização da educação básica e as conferências internacionais que versam sobre os direitos à educação, à igualdade e à diferença, introduziram no cenário político as diretrizes inclusivas. Neste sentido, o Brasil implementou uma série de leis, políticas e programas voltados para a redução da desigualdade e exclusão escolar. Inserida neste movimento, a educação especial, como área do conhecimento e conjunto de serviços, busca ressignificar-se e atualmente é defininda como:

uma modalidade de ensino que perpassa todos os níveis, etapas e modalidades, realiza o atendimento educacional especializado, disponibiliza os serviços e recursos próprios desse atendimento e orienta os alunos e seus professores quanto a sua utilização nas turmas comuns do ensino regular" (BRASIL, 2008, p. 36).

Tais diretrizes suscitaram um grande número de debates e produções voltados, dentre outros, para análise do atendimento educacional especializado, da formação de professores, do currículo, dos processos avaliativos e de gestão. Apesar destes movimentos, o acesso à escola comum não é hegemônico e ainda é amplo o desconhecimento sobre a educação escolar frente às demandas inclusivas.

$\mathrm{Na}$ construção dessas diretrizes, contudo, estudos recentes evidenciam a exclusão escolar como uma realidade ainda a ser enfrentada, sobretudo, nos primeiros anos de vida. Bueno e Meletti (2011) demonstram que o acesso à educação infantil por alunos da educação especial é ínfimo (cerca de $1 \%$ do total de matrículas) e que as matrículas concentram na préescola, sendo pequena a incidência nas creches (em torno de $25 \%$ ).

Os baixos índices de matrícula, a hegemonia dos espaços segregados sobre a inclusão escolar e a ausência de serviços especializados apontam fragilidades no processo de implementação das políticas educacionais inclusivas. Fatores que se tornam ainda mais complexos quando é amplamente conhecido que a ausência de atendimento especializado e de escolarização, desde a tenra idade, obstaculizará ou até mesmo impedirá o desenvolvimento 
psíquico, cognitivo e social de crianças em situação de desvantagem (BENINCASA, 2009; VICTOR, 2010).

Não há dúvida, assim, quanto à importância da articulação entre a educação especial e a educação infantil. Autores de áreas e perspectivas diversas enfatizam a educação infantil como espaço privilegiado para lidar com a diversidade, combater situações de desigualdade e desvantagem. Para tanto, além do acesso, faz-se fulcral analisar, refletir e produzir conhecimentos que interroguem práticas normalizadoras, reeducadoras, tão características do ensino em seus diferentes níveis e modalidades. Apesar dos ideais inclusivos, os esforços almejam ainda a adaptação e a normalização, havendo uma certeza em relação a quem são os sujeitos da educação especial e quais suas (im)possibilidades educacionais. Na construção de outra perspectiva, pensar as práticas educativas cotidianas é fundamental. Como pensá-la a partir de outras racionalidades? Quais dispositivos pedagógicos são capazes de produzir pertencimento?

Sabe-se que entre a proposição legal e a implementação das diretrizes desenhadas pelas políticas públicas de orientação ao trabalho, no campo da educação inclusiva há um caminho a ser percorrido. As práticas cotidianas precisam ser inventadas pelos professores e escolas ou, então, (re)inventadas num processo de apropriação que nunca transpõe, sem alterações, o proposto no papel para o cotidiano dos serviços e dos encontros...

Na janela, pela primeira vez, avista-se Marcello. O menino atravessa o pátio no colo do pai, envolvido cuidadosamente em uma manta de cor branca. A mãe surge um pouco mais atrás empurrando um carrinho de bebê vazio. Com perdas como a capacidade de andar, sentar e falar, decorrentes do quadro degenerativo grave, Marcello adentra a sala. Em seu corpo, as marcas de diferenças. Magreza excessiva, palidez, falta de viciosidade na pele. Movimenta somente os olhos e o pescoço. Um menino escondido atrás das faltas, do silêncio. Marcello é recebido nos braços da professora que o acolhe meio sem jeito. Os pais, mesmo aflitos, despedem-se do filho. Silêncio. Troca de olhares. Agora era Marcello, o grupo de crianças e um adulto. Em busca de conhecer e tornar-se conhecido, as primeiras palavras: "Olál Meu nome é Ana, sou tua professora." Marcello olha-a fixamente. Aparentemente não esboça nenhum sinal. O silêncio invade a sala novamente. O que a creche poderia oferecer para tal criança? Como educar e cuidar de uma criança com necessidades tão específicas? Um menino que não anda, não senta e não fala poderia aprender? Desenhar? Brincar? O que esperar?

Olhar o novo, o diferente, o outro. (Re)conhecer o enigmático. "Isso" convoca. Ligia Amaral (1998) diz do quanto a simples visão de um corpo deficiente remete-nos aos nossos piores temores, à morte e ao desejo de aniquilamento e afastamento. $\mathrm{O}$ aluno que foge ao 
ideal pode representar o desconhecido e, por vezes, o assustador. "Uma espécie de Frankenstein, uma criatura em busca de um nome diante do olhar do professor, um nome de aluno" (VASQUES, 2007, p.28).

A presença de impasses e descompassos na convivência entre os homens e os sofrimentos decorrentes do encontro com a alteridade, são temas que atravessam a psicanálise. Em diferentes textos, como, por exemplo, “O Estranho” (1919), "Psicologia do grupo e a análise do ego" (1921) e "O mal-estar na civilização" (1930), Freud aponta o inquietante sentimento de estranheza que um outro pode produzir; a formação dos grupos considerando as relações de similitude e diferença; os mecanismos de segregação na cultura advindos, por exemplo, do narcisismo das pequenas diferenças. Não se valora e tampouco se considera como semelhante qualquer um e, para ocorrer tal reconhecimento, é necessário um trabalho a fim de que a não semelhança, ou ainda, a diferença, não nos ameace.

$\mathrm{Na}$ experiência que ora se compartilha, optamos em reafirmar que, frente às dificuldades de se estar em companhia, a importância de construir um lugar para a partilha e a convivência deve ser ressaltada. Nesse sentido, a creche como uma das principais instituições responsáveis pela educação e cuidado das crianças em complementaridade à família, ocupa lugar e função fundamentais. Assim, mesmo sabendo das tensões e do mal-estar frente a presença de Marcello, apostamos na fecundidade do encontro com a alteridade no âmbito educativo a fim de germinarem novas formas de estar com o outro.

Um trabalho deveria ser realizado. Mais do que reduzir a criança a suas faltas, patologias e sintomas, torna-se necessário ampliar o olhar, promovendo encontros capazes de sustentar a função da educação e o lugar dos sujeitos que habitam tal instituição. Lajonquiere (2000) nos auxilia ao afirmar que a educação tem uma função constitutiva. Para o autor, "educar é transmitir marcas simbólicas que possibilitem a criança o usufruto de um lugar, (...) todo ato educativo submete a marcas comum ao humano na medida em que transmitem a história e filiam a cultura" (p. 63). Educar é permitir o ingresso no mundo humano. Receber, criar um lugar, pôr-se à disposição, estabelecer vínculos de filiação e de pertença entre os sujeitos. Educar é subjetivar.

Educação infantil em diálogo com a educação especial e a perspectiva inclusiva. A construção e sustentação de um lugar. O educador italiano Lóris Malaguzzi, ao pensar uma proposta para educação de crianças pequenas, coloca que esta precisa pautar-se no 
relacionamento, participação e no encontro entre professores, crianças e famílias. Para tanto, o projeto italiano propõe a "Pedagogia da relação":

\footnotetext{
A pedagogia da relação é uma intervenção educativa que age sobre o sistema de trocas sociais, utilizando-o através das relações que progressivamente se entrelaçam entre a criança e os adultos - entre crianças no grupo de jogo - cria-se um conjunto de significados compartilhados, uma espécie de 'história social. (BONDIOLI e MANTOVANI, 1999, p.29).
}

A socialização, as interações e as aprendizagens entre adultos e crianças são pilares que sustentam essa pedagogia. Adultos e crianças são co-protagonistas do processo educativo. A criança é lida como sujeito potente, ativo e inventivo. O professor, parceiro mais experiente, é convocado a ler, reconhecer, valorizar, mediar e documentar, ofertando possibilidades educacionais que potencializem o desenvolvimento psíquico, cognitivo e social. Como construir tais pressupostos no cotidiano com Marcello, seus familiares e a outras crianças?

\section{TEMPOS DE OBSERVAÇÃO E ESCUTA SENSÍVEL...}

No centro da roda, outro dia é inventado. Crianças eufóricas contam sobre o final de semana: teve mar, sol, visita na casa da avó, jogo de futebol. Passeio na praça, na casa da madrinha. Banho de piscina. A conversa corre solta, voa nas asas da imaginação. Olhar, interesse e atenção funcionam como convites para narrativas de ricas experiências. Após um tempo, uma criança do grupo fala: "Professora o Marcello não fez nada na casa dele, né? Ele não conta nada..." Todos param. As crianças aguardam uma resposta. A professora percebe um acontecimento importante. Com a voz embargada, um pouco sem jeito, ainda sem saber direito o que e como dizer, afirma: "Marcello não pode contar o que faz pela fala, mas pode falar de outras formas... O olhar, o sorriso, o choro podem nos dizer sobre ele... Que tal se o ajudássemos a contar?" Propõe, então, a criação de um Diário de e para Marcello. Um diário onde contariam à família o que Marcello fez na creche e a família, por sua vez, registraria as experiências em casa. Todos passariam a escrever a história. A nossa história. Um escrito sustentado por muitas mãos e vozes. Marcello também passaria a ter finais de semana...

A flexibilização de processos pedagógicos remete a pensarmos, inicialmente, sobre quem são as crianças com deficiências e como as acolhemos. Abandonar os caminhos mais rápidos, assumir que nosso conhecimento é limitado e colocar-nos no lugar de quem não sabe tudo do outro porque nossa criança não é óbvia, não é uma obra clara, é sempre um grande 
desafio. No sentido de criar possibilidades educativas que permitam conhecer, respeitar e valorizar as diferenças de cada criança, a pedagogia italiana propõe a documentação pedagógica. Uma forma singular de ler, inscrever e estar em companhia.

O termo "documentação pedagógica" insere-se em uma proposta que considera a importância da escuta, da observação e do registro para conhecer as crianças (MALAGUZZI, 1999). O ato de documentar, nessa perspectiva, configura-se como um "processo cooperativo que ajuda professores a escutar as crianças com quem trabalham." (GANDINI e EDWARDS, 2002, p.84).

Para Davoli (2008), documentar é fundamental para dar visibilidade às experiências das crianças. Diante da multiplicidade e riqueza envolvida no ato de documentar ${ }^{3}$, propomos nesse texto a documentação pedagógica como um processo narrativo, o qual para além de dar visibilidade às experiências das crianças, constitui experiência com elas (SIMIANO, 2015).

Nessa perspectiva, a documentação pedagógica contribui significativamente para a construção da identidade da criança. Malaguzzi (1995) recorrendo a história de "Alice no país das maravilhas", afirma a necessidade de os adultos proverem às crianças uma identidade. O autor retoma a história, recordando a menina diante de sua confusão, deitada no chão, necessitando de alguém que lhe diga quem ela é para se por de pé. “As crianças assim como Alice, necessitam de alguém que lhes cubra de palavras, que lhes de um nome e as tirem do anonimato". (MALLAGUZZI, 1995, p.98) Para ele é fundamental que os adultos nomeiem, emprestem palavras e narrem uma história para a criança conferindo-lhe uma identidade

A construção da identidade está profundamente engendrada no social, coloca Ricouer (1994). Ela identifica o sujeito como membro de uma comunidade e, ao mesmo tempo, o revela como ser singular. O autor, ao levantar a questão "Quem sou eu?" sugere como caminho de resposta "é preciso começar a narrar", pois é “a narrativa que sustenta, a tese do não ser" (RICOUER, 1994). A narrativa no trabalho com crianças pequenas implica uma experiência processual onde o narrador está constantemente emprestando-se como co-autor do

\footnotetext{
${ }^{3}$ BENATI, (2005); BENZONI,(2001); PASQUALE, (2002); SPECCHIA, (2002), entre outros indicam a importância do ato de documentar: documentar para constituir memória; documentar para identidade; documentar para dar visibilidade ao projeto educativo; documentar para avaliar o trabalho; documentar para comunicar; documentar como fonte de pesquisa sobre a ação docente; documentar como fonte de informação e de conhecimento; documentar para refletir sobre a prática; documentar para construir da identidade profissional entre outros.
} 
narrado. Ao narrar a criança, o professor possibilita a construção de uma identidade e, ao mesmo tempo, torna-se co-autor da história do sujeito. Trata-se da constituição de uma experiência compartilhada. Daí seu poder de criar laços identitários.

Nesta perspectiva, Benzoni (2001) destaca o peso da palavra, no processo de documentação pedagógica enquanto marcas significativas na identidade e história de vida da criança. Agregando provas, testemunhos esse processo oferece referências à história e à memória, subjetiva e coletiva de um grupo. O autor aponta a memória como possibilidade de adultos e crianças revisitar, reconstruir, ressignificar, criar... Um entendimento de memória não como recuperação, mas como produção (MOSCHEN 2005), que permite tomar a história como possibilidade e não como determinação.

Nessa perspectiva, a documentação pedagógica, não se constitui em uma ação neutra. Documentar requer observar, escutar, registrar, interpretar, narrar... Escolhas que implicam construção de significados e revelam sobre relações entre professores e crianças.

Donatella Giovaninni propõe "o diário de duas vozes" como uma forma de documentação pedagógica que oferece uma oportunidade única de (re)construir o processo de crescimento das crianças. Para a autora "esses diários são compostos por notas, histórias, geralmente curtas e rápidas, as quais registram o crescimento e o desenvolvimento das crianças, além de promoverem reflexões e ideias." (GIOVANNINI, 2002, p.171)

As "vozes do diário" são compostas pelas crianças, professores e familiares e possibilitam diversas leituras. Textos, imagens e outras produções estabelecem diálogos, ampliam significados e possibilitam revisitar e constituir experiências significativas.

Na construção do diário de Marcello, a observação e registro não se davam apenas em grandes acontecimentos, datas comemorativas, mas ao contrário, as páginas ilustravam a força dos pequenos acontecimentos do dia-a-dia. Diante da impossibilidade de falar diretamente sobre suas experiências, tornava-se necessário que outros contassem a riqueza de sua história. Professora, crianças e familiares eram, simultaneamente, testemunhas, autores e leitores de uma história que estava para ser inscrita a cada encontro. Através do diário tornava-se possível conhecer e inventar um outro Marcello. Um menino contado, narrado, não apenas pelas faltas e limitações decorrentes de sua doença degenerativa, mas pelos seus desejos, curiosidades e vontade de vida. 


\section{TEMPOS DE LER, REGISTRAR E NARRAR...}

Brincar, imaginar, inventar. Na sala "cantinhos" foram organizados com os mais variados objetos. Espaços de brincadeiras. A mãe de Marcello havia registrado o medo e o choro do filho ao frequentar consultórios médicos e odontológicos, em função das inúmeras experiências vividas em clinicas e hospitais. Na sala um espaço, intitulado pelas crianças como "cantinho da saúde", foi organizado. Um banco para deitar, jaleco branco, estetoscópio, maleta, máscara, luvas e seringa hospitalar. Marcello observa de longe. Maria Clara coloca uma pequena boneca embaixo de sua camiseta, deita-se na maca e diz: "Estou com bebê na barriga! Socorro, alguém, me ajude!" Gabriela aproxima-se, coloca uma almofada em sua cabeça e diz: "Fique calma, eu sou a enfermeira, vou te ajudar. Precisarei de um médico!" As meninas se olham e perguntam: "quem poderá ser 0 médico?". Gabriela fala: "Ah! Já sei! O Marcello pode ser o médico!" E logo aproxima sua cadeira de rodas a esse espaço, coloca o estetoscópio no pescoço de Marcello, a maleta em seu colo e a máscara no seu rosto. Marcello sorri, troca olhares intensos com as colegas, balbucia e esforça-se para realizar movimentos com os braços. No encontro, na interação e na brincadeira, pequenos leitores inscrevem outras histórias, inventando novas armas para as inúmeras batalhas do dia-a-dia...

A presença de crianças com deficiências em instituições educativas infantis é marcada por práticas objetivadoras, pautadas nas limitações e faltas. A ausência de atendimento educacional especializado, a comparação e normalização presentes em alguns instrumentos pedagógicos criam rótulos, invisibilizando, ou até mesmo impedindo, a construção do sentido de pertencimento.

Referente às Diretrizes Curriculares Nacionais da Educação Infantil (2012), é preciso assumir processo de observação, registro e análise do contexto educativo como parte inerente da prática pedagógica, onde o cotidiano se constitui como cenário a ser conhecido. A observação sistemática a partir de múltiplos registros (relatórios, fotografias, desenhos, álbuns, etc.), feitas ao longo do período, em diversificados momentos na instituição, são condições necessárias para compreender como a criança se apropria do mundo. Conhecer as preferências, as formas de participação nas atividades, seus parceiros prediletos, suas narrativas, podem auxiliar o professor a reorganizar a prática pedagógica de modo mais adequado ao alcance dos propósitos infantis e das aprendizagens coletivamente trabalhadas.

Barbosa (2009) procurando discutir a educação das crianças, em diálogo com as Diretrizes Curriculares Nacionais para a Educação Infantil, enfatiza alguns aspectos 
necessários no trabalho pedagógico. As relações interpessoais, a linguagem e a brincadeira se constituem em eixos fundamentais da pedagogia na educação infantil.

Relações interpessoais. (Re)conhecer a presença do outro, ser reconhecido por ele. $\mathrm{O}$ diário de Marcello, pouco a pouco, contava histórias sobre formas de olhar e ser olhado. O olhar é constitutivo. Maria Clara e Gabriela ao olharem para Marcello e o reconhecerem como personagem, protagonista, sujeito potente, capaz de brincar, o convocam à vida. Marcello, já não era mais lido como indiferente, mas como alguém que (co)responde ao ser visto.

A sintonia do olhar entre Marcello, Maria Clara e Gabriela parece estabelecer um tipo relação entre eles, onde é possível perceber que partilham um entendimento entre si. Entendem o outro e se fazem entender, no encontro de olhares, sintonia e sensibilidade. Olhar o outro, acompanhar movimentações, sorrir dá indícios de que Marcello mesmo sem falar, se comunica, brinca e constitui, nas relações em grupo, a capacidade de diálogo e de nãoindiferença ao outro. Tais aspectos podem e devem ser considerados na organização das práticas educativas cotidianas. São pistas importantes para a condução do trabalho e compreensão do percurso individual e grupal. O professor, nesse sentido, atua como leitor e testemunha destes acontecimentos. Ao olhar para as crianças, registrar e documentar esses olhares, encontros e cenas possibilitam leituras distintas de Marcello. Leituras e sentidos que reconhecem sua alteridade como presença significativa.

Linguagem. A criança é feita de cem... Tem cem linguagens e por isso, cem formas de se comunicar (MALLAGUZZI, 1999). O olhar, o toque, o sorriso... Para conhecer o espaço e interagir com o outro, Marcello se utilizava de muitas linguagens. Embora sem poder expressar-se pela fala, no encontro com o mundo, nas e pelas mais variadas linguagens, o menino brinca, aprende e ressignifica experiências. Observar, reconhecer, interpretar e narrar as diferentes formas de comunicação de Marcello significa valorizá-lo como sujeito capaz, competente e com capacidade de nos dizer algo sobre si mesmo.

Brincadeira. A principal forma de a criança ser, estar e se relacionar com mundo. Uma experiência educativa na qual se aprende e colocar-se como sujeito. Retomando o fragmento da brincadeira entre Maria Clara, Gabriela e Marcello, podemos perceber a presença de aspectos que envolvem aprendizagens variadas - as crianças se comportam de acordo com seu papel e com as ideias gerais que definem o universo simbólico da brincadeira. Ao assumir o papel de médico, Marcello passa a não chorar mais, sorri diante dos objetos hospitalares e busca tentar manipulá-los. A brincadeira de médico permitiu a Marcello ressignificar suas experiências. Da ausência ao protagonismo. Do medo à alegria de brincar. Do paciente ao 
médico. A mudança, a renovação da experiência humana por meio do brincar. A professora de Marcello ao ampliar tempos, espaços, materiais e documentar esse processo possibilitou a criação de cenários, personagens e narrativas. Verdadeiros convites que abrem caminhos para fazedores de histórias no mundo.

A partir dos eixos citados acima, as Diretrizes Curriculares Nacionais para educação infantil trazem indicações referentes à criação de procedimentos para acompanhamento do trabalho pedagógico com as crianças onde se busca garantir:

\begin{abstract}
A observação crítica e criativa das atividades, das brincadeiras e interações das crianças no cotidiano; Utilização de múltiplos registros realizados por adultos e crianças (relatórios, fotografias, desenhos, álbuns etc.); A continuidade dos processos de aprendizagens por meio da criação de estratégias adequadas aos diferentes momentos de transição vividos pela criança (transição casa/instituição de Educação Infantil, transições no interior da instituição, transição creche/pré-escola e transição pré-escola/Ensino Fundamental); Documentação específica que permita às famílias conhecer o trabalho da instituição junto às crianças e os processos de desenvolvimento e aprendizagem da criança na Educação Infantil. (BRASIL, 2010, p. 12.Grifos nossos).
\end{abstract}

Nesse recente documento pode-se perceber a importância da documentação na organização do trabalho pedagógico com as crianças. O diário de Marcello possibilita olhar para as brincadeiras e interações das crianças no cotidiano sob outra perspectiva. Ao invés de discursos sobre a criança, sobre o professor e sobre a creche, a documentação pedagógica se configurou como um modo peculiar de desvelar sentidos, constituir aprendizagens e narrar.

Para Benjamin (1986), a narração emerge de um sentido prático. Ela traz ensinamentos, referências úteis à vida cotidiana. Nas palavras do autor, a verdadeira narrativa “tem sempre em si, às vezes, de forma latente, uma dimensão utilitária (...) o narrador é um homem que sabe dar conselhos” (p. 201). Então, surge a pergunta: Seria o professor um narrador para as crianças? Afinal, não é ele que ao registrar e narrar o cotidiano, possibilita a produção de sentidos?

É possível estabelecer uma relação entre a figura do narrador e do professor, coloca Vasconcellos (2005). Para a autora, o próprio Benjamin diz isso e o faz com todas as letras quando localiza o narrador na figura entre os mestres e os sábios. Apenas a autora faz uma reflexão com relação à palavra mestre, a qual para ela é passível de interpretação. 
outros pode vir a ser um mestre. Mas o simples fato do exercício desse ofício não o torna um deles. Isso porque o mestre não ensina algo. O conteúdo de sua narrativa é a totalidade de sua experiência. É ele próprio. Sua vida que é entregue incondicionalmente ao banquete dos bárbaros - para que devorem tudo e que disso possa resultar algo de decente. (VASCONCELOS, 2005, p. 98).

Pensar a narrativa em contextos de educação coletiva permite vislumbrar o laço que une crianças e adultos a uma rede de significantes comuns. A narrativa ou palavraexperiência, não se trata de uma palavra convencionada, mas de uma palavra tácita, que se presentifica e apresenta-se no representado. Assim, podemos dizer que, quando o professor narra, ele converte "a vida em narrativa e a narrativa em vida", possibilitando às crianças uma produção de sentidos e significados que influenciam a sua trajetória de vida.

Para Benjamin (1986), a origem da narrativa é a experiência humana. É sobre ela que o narrador transforma a própria experiência em algo útil para os outros. No gesto de documentar, a professora cria visibilidades, não apenas para o que é aparente, pois "o significado documental não surge da mera observação. É sempre um ato interpretativo em que o documentador se implica autobiograficamente - no processo documental". (HOYUELOS, 2006, p.203) Nessa perspectiva, a documentação pedagógica, não pode ser compreendida como simples coleta e agrupamento de episódios isolados, visando dar informações que tem como produto um relatório. Implica em um processo que diz respeito ao uso desse material, a forma como ele é coletado, refletido, interpretado, inventado e, sobretudo, narrado.

Benjamin (1994) ao estabelecer relações entre experiência e narrativa, afirma o vínculo entre o episódio narrado e a vida do narrador "se imprime na narrativa a marca do narrador, como a mão do oleiro na argila do vaso" (p. 227). A narração não está interessada em apenas transmitir "o puro em si" da coisa narrada como um relatório. Segundo o autor, a informação só tem valor quando é nova, a verdadeira narrativa, pelo contrário, depois de muito tempo é capaz de suscitar espanto e reflexão. Portanto, a arte de narrar está no fato da narrativa evitar explicações. Quem ouve é livre para interpretar a história, expandindo a amplitude do que foi narrado.

Em contraposição à informação, a narração prescinde de explicações, deixando ao interlocutor a liberdade de interpretação. Acreditamos que tal movimento permite deslocar a posição do professor e da criança em relação a um ideal perdido (de criança, de intervenção) para um fazer encontros possíveis. Marcello, seus pais, professora e colegas inscrevem nas páginas do Diário tal deslocamento: se não há fala ou movimento como os esperados nos 
padrões da normalidade, há olhares, sentidos, gestos a serem inventados, decifrados, valorados, ressignificados. Não mais uma estereotipia típica do quadro degenerativo, quem sabe um chamado? Ou talvez, o desejo de estar com o outro?

No presente trabalho propomos a documentação como uma narração. Pequenos contos que possibilitam às crianças e aos adultos caminharem por viagens (eufharem), lugares conhecidos e desconhecidos. Na documentação, a narrativa não se completa. Fios ficam soltos, convidando a novas tramas, abrindo possibilidades de produção de sentidos e significados. Histórias preciosas as quais se não forem narradas correm o risco de se perder (SIMIANO, 2015).

Pouco a pouco a página em branco do diário cedeu lugar a letra. Palavras e imagens narravam, inventando histórias. Nas páginas da escola: Um mergulho na piscina de bolinhas. Brincando de médico. Aventuras no parque. O passeio de ônibus. Um aluno. Uma professora. Uma escola. Colegas. Nas páginas de casa: Visita na casa do avô. Passeio na praia com a mãe e o pai. Brincadeiras com o cachorro Simba. Visita ao Clube do Internacional, timão do coração de Marcello. Um filho. Páginas de vida que escreveram e compartilharam.

Frente a fragilidade da condição humana e as desmesuras do humano, apostamos na palavra como forma de construir outros sentidos e possibilidades de pertencimento. Nesse sentido, a educação infantil possui lugar e função fundamental. Desde a mais tenra idade, o encontro com a alteridade é capaz de criar novas formas de estar e habitar o mundo. Para tanto, deslocar do aluno ideal à construção de um possível, é necessário um longo e delicado trabalho. No presente texto, a partir do relato de uma experiência em educação infantil na perspectiva da educação inclusiva, apresentamos um fragmento, uma breve cena, que apostamos significativa para compor outra narrativa sobre o ser professor e o estar na escola. Sabemos o quanto a organização das práticas pedagógicas cotidianas é um dos principais nós na pedagogia. Na presença de uma criança pequena, com severas limitações físicas, tal nó pode ser ainda mais significativo. O que fazer com quem parece não falar, não brincar, não correr? Como garantir não só o acesso, mas o lugar de criança, de professor, de colega, diante de tamanhas faltas e perdas? Como fazer se o trabalho caminha em direção ao desenvolvimento e constituição subjetiva se o que aparece inicialmente são as perdas, os nãos? Assumir a documentação pedagógica como um processo narrativo nos lança em uma 
SIMIANO, L. P.; VASQUES, C. K.

zona estranha, incerta e fascinante. Um convite a inverter o olhar e pensar uma lógica que vê e narra a pequena criança e sua deficiência não como faltosa ou inábil, mas como força, potência e possibilidade. Essa é a nossa aposta...

\title{
BETWEEN WORD AND LIFE: A READING ABOUT PEDAGOGICAL DOCUMENTATION AND NARRATIVE IN THE CONTEXT OF INCLUSIVE EARLY CHILDHOOD EDUCATION
}

\begin{abstract}
This text discusses the pedagogical documentation as a narrative journey, a peculiar form of reading the daily, sustain the meeting, being in relationship. From an experience in early childhood education, the empirical data analyzes part of a documentation, built with a child included, colleagues and family. Against the losses of severe degenerative health status was necessary to give words, pictures, gestures, visibilities and senses alert to pulsating life in the boy. This proposition was realized from the dialogue between the philosophy of Walter Benjamin, psychoanalysis, the right to education and the Italian pedagogy. The dairy wrote the school history of Marcelo as a possibility and not has been determined; was the teacher as a narrator, attentive to detail, the remains and silences. Think documentation as narrative throws us into a strange, uncertain and fascinating area. An invitation to reverse the look and think a logic that sees and tells the young child and his disability not as defaulting or awkward, but as strength, power and possibility.
\end{abstract}

Keywords: Early Childhood Education; School Inclusion; Pedagogical Documentation. Narrative

\section{ENTRE PALABRA Y VIDA: UNA LECTURA SOBRE DOCUMENTACIÓN PEDAGÓGICA Y NARRATIVA EN EL CONTEXTO DE EDUCACIÓN INFANTIL INCLUSIVA}

\begin{abstract}
Resumen
En este trabajo, se analiza la documentación pedagógica como un recorrido narrativo, una manera peculiar de leer lo cotidiano, sostener el encuentro, estar en relación. A partir de una
\end{abstract}


experiencia en la educación infantil, el material empírico analiza parte de una documentación, construida en conjunto con un niño incluido, sus compañeros y familiares. Teniendo en cuenta las pérdidas de corrientes de un episodio degenerativo grave, era necesario ofrecer palabras, imágenes, gestos, puntos de vista y sentidos atentos a la vida pujante del niño. Tal propuesta se realizó a partir del diálogo entre la filosofía de Walter Benjamin, el psicoanálisis, el derecho a la educación y la pedagogía italiana. Escribir un diario colocó la historia escolar de Marcello como una posibilidad y no como determinación; colocó al maestro como un narrador, atento a los detalles, a los restos y a los silencios. Pensar la documentación como narrativa nos pone en una zona extraña, incierta y fascinante. Una invitación a revertir la mirada y pensar una lógica que ve y narra a un niño y su discapacidad no como falla o ineptitud, sino como fuerza, potencia y posibilidad.

Palabras clave: Educación infantil; Inclusión escolar; Documentación pedagógica; Narrativa

\section{REFERÊNCIAS}

ADORNO, Theodoro W. O ensaio como forma. In: Notas de literatura I. São Paulo: Editora 34, 2003.

AMARAL, Ligia. Sobre crocodilos e avestruzes: falando de diferenças físicas, preconceitos e sua superação. In: AQUINO, Júlio G. (Org.). Diferenças e preconceitos na escola. São Paulo: Summus, 1998.

BARBOSA, Maria Carmen S. A prática pedagógica na creche. Disponível em: http://www.concepto.com.br/mieib/.../w-texto_maria_carmem_barbosa.pdf. Acesso em: 10 Mar. 2015

BENINCASA, Melina C. Educação Especial e Educação Infantil: uma análise de serviços especializados no Município de Porto. Porto Alegre, 2011. 123 f. Dissertação (Mestrado em Educação) - Programa de Pós-Graduação em Educação, Faculdade de Educação, Universidade Federal do Rio Grande do Sul, Porto Alegre, 2011.

BENJAMIN, Walter. Magia e técnica, arte e política. Obras escolhidas I. 2. ed. São Paulo: Brasiliense, 1986.

BENJAMIN, Walter. Rua de mão única. Obras Escolhidas II.4. ed. São Paulo: Brasiliense, 1994.

BENZONI, Isabella. La documentazione e le sue funzioni. In: BENZONI, I. (Org.). 
Documentare? Sì, grazie. Ranica: Junior, 2001.

BONDIOLI Anna. MANTOVANI Suzanna. Pedagogia das relações. In: EDWARDS, C. P. As cem linguagens da criança:a abordagem de Reggio Emilia na educação da primeira infância. Porto Alegre: Artmed, 1999.

BRASIL. Presidência da República. Casa Civil. Lei no 9.394/1996. Lei de Diretrizes e Bases da Educação Nacional. Brasília, DF: Diário Oficial 23 dez 1996.

BRASIL. Ministério da Educação. Política Nacional de Educação Especial na Perspectiva da Educação Inclusiva. Brasília: MEC/SEESP, 2008.

BRASIL. Conselho Nacional de Educação. Resolução CNE/CEB nº 4/2012. Diretrizes Curriculares Nacionais Gerais para a Educação Básica. Brasília, DF: Diário Oficial da União, 14 jan de 2015.

BUENO, José Geraldo Silveira; MELETTI, Silvia Márcia Ferreira. Educação infantil e educação especial: uma análise dos indicadoes educacionais brasileiros. Revista Contrapontos, Itajaí: Univali, v. 11, n. 3, p. 278-287, out. 2011. http://dx.doi.org/10.14210/contrapontos.v11n3.p278-287. Acesso em: 10 Mar. 2015

DAVOLI, Mara. Documentar processos, recollir trces In ALTIMIR, David; BONÀS, Meritxell; DAVOLI, Mara; DOLCI, Mariano. Documentar la vida dels infants a l'escola. Barcelona: Rosa Sensat, 2008

FREUD, Sigmund. O Estranho. In: Edição Standard Brasileira das Obras Psicológicas Completas de Sigmund Freud. Vol.XVII. Rio de Janeiro: Imago,1976 (original de 1919).

Psicologia de grupo e a análise do ego. In: Edição Standard Brasileira das Obras Psicológicas Completas de Sigmund Freud. Vol. XVIII.Rio de Janeiro: Imago, 1976 (original de 1921).

O mal-estar na civilização. In: Edição Standard Brasileira das Obras Psicológicas

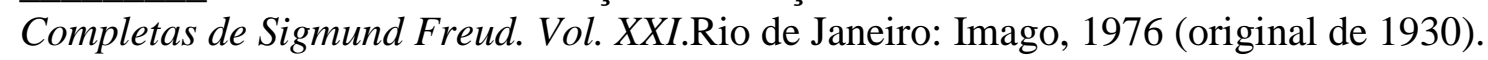

GANDINI, Lella. História, Ideias e Filosofia Básica. Entrevista com Lóris Malaguzzi. In: EDWARDS, C. P. Bambini:a abordagem italiana à educação infantil. Porto Alegre: FGV, 2002. cap. 2, p. 59-104

GIOVANNINI, Donatella. Características da Infância: Diário de uma criança. In:

EDWARDS, C. P. Bambini:a abordagem italiana à educação infantil. Porto Alegre: FGV, 2002. cap. 11, p. 171-179

HOYUELOS, Alfredo. La estética en el pensamiento y obra pedagógica de Loris Malaguzzi. Barcelona: Octaedro, 2006.

KUPFER, Mara.C.Educação para o futuro: psicanálise e educação. São Paulo: Escuta, 2000. 
LAJONQUIÉRE, Leandro. Itard Victor!!! Ou o que não deve ser feito na educação das crinaças. In: BANKS-LEITE, L; GALVÃO I. (org). A educação de um selvagem: as experiências pedagógicas de Jean Itard. São Paulo: Cortez, 2000.

LARROSA, Jorge. O ensaio e a escrita acadêmica. Revista Educação \& Realidade, Porto Alegre, vol.28, n.2, 2003.

MALAGUZZI, Lóris. Escuelas infantiles de Reggio Emilia: La inteligencia se construye usándola. Madrid: Ediciones Morata, 1995.

MALAGUZZI, Lóris. Histórias ideias e filosofia básica. In: EDWARDS, C; GANDINI, L.; FORMAN, G. As cem linguagens da criança. Porto Alegre: Artes Médica, 1999.

MOCHEN, Simone. A construção da memória e a condição da perda. Revista Horizontes, São Paulo: Universidade de São Francisco, v.23, n. 1, p. 39-46, jan/jun.2005.

http://webp.usf.edu.br/edusf/publicacoes/RevistaHorizontes/Volume 03/uploadAddress/horiz ontes-5[6254].pdf. Acesso em: 10 Mar. 2015

RICOUER, Paul. Tempo e Narrativa. Campinas, SP: Papirus, 1994, 3 tomos.

RINALDI, Carla. Diálogos com Reggio Emília: Escutar, Investigar e Aprender. Paz e Terra, 2012.

SIMIANO, Luciane P. Colecionando pequenos encantamentos... A documentação pedagógica como uma narrativa peculiar para e com crianças bem pequenas. 198 p. Tese (Doutorado em Educação) - UFRGS. Porto Alegre. 2015.

VASQUES, Carla K. Um estrangeiro entre nós, Psicanálise e Educação Especial: diálogos em torno da inclusão de crianças que vivem impasses em sua constituição psíquica. Ponto de Vista, Florianópolis: UFSC, n. 9, 2007.

http://www.periodicos.ufsc.br/index.php/pontodevista/article/view/20422/18656. Acesso em: 10 Mar. 2015

VICTOR, Silvio. Sobre inclusão, formação de professores e alunos com necessidades educacionais especiais no contexto da educação infantil. In: BAPTISTA, C.; JESUS, D. Conhecimentos e margens: ação pedagógica e pesquisa em educação especial. Porto Alegre: Mediação, 2010. 